\title{
Nutritional and physical requirements for mycelial growth and basidiocarp production of Trametes elegans from the Philippines
}

\begin{abstract}
Rich Milton R. Dulay ${ }^{1,2 *}$, Abegail A. Alcazar ${ }^{1}$, Sofronio P. Kalaw ${ }^{1}$, Renato G. Reyes ${ }^{1}$, Esperanza C. Cabrera ${ }^{2}$
${ }^{1}$ Center for Tropical Mushroom Research and Development, Department of Biological Sciences, College of Science, Central Luzon State University, Science City of Munoz, Nueva Ecija, 3120 Philippines

${ }^{2}$ Department of Biology, College of Science, De La Salle University, Taft Avenue, Manila, Philippines

Abstract

This paper highlights the rescue and optimal cultural conditions of the naturallyoccurring Trametes elegans. This mushroom has white fan-like leathery fruiting body that commonly grows singly on deadwood. The secondary mycelial culture has offwhite, velvety texture, and aerial hyphae. Rice bran broth agar with $\mathrm{pH}$ ranging from 5.5 to 6.5 , incubated in either lighted or dark, at $30^{\circ} \mathrm{C}$, and sealed conditions were the optimum nutritional and physical factors for growth. Both cracked corn and sorghum seeds registered as the best substrates for grain spawn production. Four parts of sawdust + six parts of rice straw significantly produced the highest yield (12.03 g) and biological efficiency $(2.41 \%)$. Enriched cultivation study using supplemented substrates is currently under investigation with the aim to increase the production.
\end{abstract}

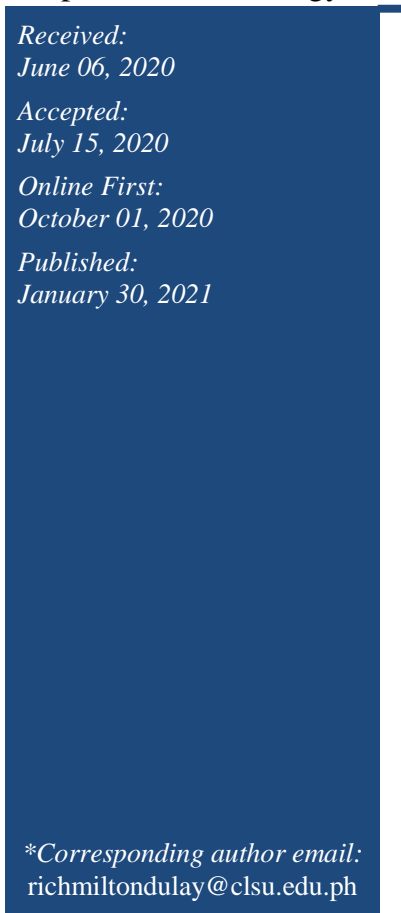

Keywords: Trametes spp., Secondary mycelia, Basidiocarp, Philippine wild mushrooms, Optimized culture conditions

\section{How to cite this:}

Dulay RMR, Alcazar AA, Kalaw SP, Reyes RG and Cabrera EC, 2021. Nutritional and physical requirements for mycelial growth and basidiocarp production of Trametes elegans from the Philippines. Asian J. Agric. Biol. 2021(1). DOI: https://doi.org/10.35495/ajab.2020.06.339

This is an Open Access article distributed under the terms of the Creative Commons Attribution 3.0 License. (https://creativecommons.org/licenses/by/3.0), which permits unrestricted use, distribution, and reproduction in any medium, provided the original work is properly cited.

\section{Introduction}

Mushrooms are macrofungi with distinct sporebearing structure called the sporocarp or basidiocarp, which can either be seen hypogeously or epigeously (Chang and Miles, 1992). The existence of many species of naturally-occurring macrofungi in the Philippine is attributable to the presence of massive lignino-cellolusic substrates and the fine climatic conditions. They are commonly found growing on leaf litters, fallen logs and branches, deadwoods, lawns, soil, dead insects, termite's mound, and even on the piles of agro-industrial substrates. However, most of these macrofungi remain relatively unexplored, and their optimal culture conditions necessary to the development of sustainable production techniques are not yet established. It is therefore imperative to continuously collect and domesticate Philippine strains of mushrooms before their extinction because they could be important sources not only of nutritious food, but also of natural medicine. Moreover, mushroom cultivation using practical production technology can generate income for mushroom growers and farmers, which will contribute to strengthening the mushroom industry in the Philippines. 
The genus Trametes is one of the naturally-occurring macrofungi, and the different species have been reported to inhabit the different areas of the Philippines based on the macrofungal listing. Trametes corrugata and T. versicolor, for instance, were documented in Angat Watershed Reservation, Bulacan while T. elegans was found in Mt. Mingan, Nueva Ecija (Liwanag et al., 2017; Guzman et al., 2018), but their mycelia were not rescued. However, just recently, another wild strain of Trametes was also found in Nueva Ecija and was successfully rescued and molecularly identified as Trametes elegans. This white rot macrofungus has a thick white, leathery, fanshaped fruiting body that is naturally growing on deadwoods, fallen logs and branches of trees. Extract of this wild fruiting body contains bioactive compounds and exhibits antibacterial, antioxidant, and cytotoxic effects (Nanglihan et al., 2018).

Most of the reported studies regarding utilization of Trametes species have focused on ligninolytic enzyme production such as laccase, synthetic dye decolorization, polysaccharide production, chemical composition elucidation and biological activity evaluation (Trupkin et al., 2003; Tavares et al., 2005a; b; Jing et al., 2007; Cui and Chisti, 2003; Johnsy and Kaviyarasana, 2011; Kamiyama et al., 2013; Aina et al., 2016). Some biological activities of this genus include anti-tumor, antibacterial, anti-oxidant, and anti-proliferative properties exhibited by $T$. gibbosa extract (Ren et al., 2006; Shahbazyan et al., 2017). Trametes versicolor, the most famous medicinal species of Trametes, has potent anti-human immunodeficiency virus, anti-inflammatory, antioxidant, antigenotoxic and immuno-stimulatory effects (Collins and Ng, 1997; Kamiyama et al., 2013; Knezevic et al., 2015; Chu et al., 2002). This species can also be a source of an antifungal agent against wood-decaying fungi (Teoh and Mashitah, 2012).

Although one work was conducted to optimize the cultural conditions of $T$. elegans for the improved production of antifungal substances in a liquid culture (Liu et al., 2016), optimization of the growth requirements in solid-state conditions is still of our interest since this mushroom grows naturally on solid substrate. Apparently, there are no reports dealing with the optimization of the nutritional and environmental requirements for the growth of mycelial and fruiting body of T. elegans in solid-state conditions, which are important parameters in the generation of production technology, hence this work. The aim of the study was to evaluate the growth of mycelia on the different culture media, physical factors, and grain spawning materials, and the production of fruiting body of $T$. elegans using rice straw and sawdust as substrates.

\section{Material and Methods}

\section{Source of mushroom and tissue culture}

The wild fruiting body of $T$. elegans (Figure 1) growing on the dead trunk of acacia (Pithecellobium saman (Jacq.) Benth) was collected from Lingap Kalikasan Park in Central Luzon State University Campus, Science City of Munoz, Nueva Ecija, Philippines. The sample was brought to the laboratory for tissue culture on potato dextrose agar (PDA). Pure cultures were used as inoculants source in the growth performance assays.

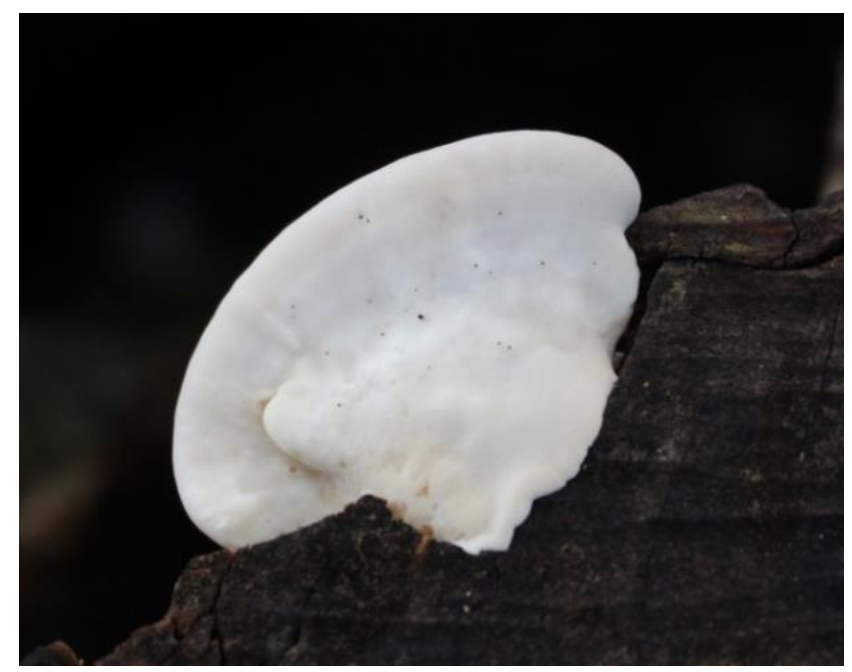

Figure-1. Wild fruiting body of Trametes elegans on the dead trunk of acacia.

\section{Evaluation of culture media and $\mathrm{pH}$}

Four indigenous culture media namely; coconut water agar (CWA), rice bran broth agar (RBBA), corn grit broth agar (CGBA) and potato broth sucrose agar (PBSA) were prepared as described by Dulay et al. (2012a). The $10 \mathrm{~mm}$-diameter mycelial disc from a seven-day old pure culture was inoculated centrally onto each plated medium and incubated at $30^{\circ} \mathrm{C}$ under alternating light and dark conditions. The mycelial growth rate was determined in five days of incubation. The most favorable medium was adjusted to different $\mathrm{pH}$ levels (from 5.0 to 8.0 with 0.5 intervals) using $0.1 \mathrm{M} \mathrm{NaOH}$ or $0.1 \mathrm{M} \mathrm{HCL}$ to determine the optimum $\mathrm{pH}$. Each treatment of both set-ups was replicated three times. 


\section{Influence of physical factors}

Mycelial discs were inoculated on plates containing the best medium at optimum $\mathrm{pH}$ and evaluated the three physical factors namely; illumination, temperature and aeration. In illumination, plates were incubated in lighted and total dark conditions. To determine the optimum temperature, plates were incubated at $30^{\circ} \mathrm{C}, 20^{\circ} \mathrm{C}$, and $10^{\circ} \mathrm{C}$. Finally, in aeration, plates were incubated in sealed and unsealed conditions. The growth rate of mycelia on the different physical factors was recorded. All tests were replicated three times.

\section{Evaluation of spawning materials}

In spawn production, three granulated materials such as cracked corn, rice seeds and sorghum seeds were evaluated as substrate for grain spawn production of $T$. elegans. The preparation of grain substrates, inoculation of mycelia and incubation conditions were similar to the procedure of Dulay et al. (2012a). Incubation period and mycelia density were noted. The best grain substrate was determined and used for mass production, which served as inoculant in the evaluation of fruiting body performance.

\section{Evaluation of fruiting body production}

Sawdust and rice straw were used as the basal substrate and the different formulations were prepared following the formulations described by Dulay et al. (2017). Fruiting bags were inoculated with $40 \mathrm{~g}$ of grain spawn and subsequently incubated at $30^{\circ} \mathrm{C}$. Incubation period was recorded. The fully ramified bags were opened at one end and watered three times a day. The yield was recorded, and the percentage biological efficiency was computed.

\section{Statistical analysis}

Data were analyzed using analysis of variance (ANOVA). Treatment means were compared using Tukey's HSD at 5\% level of significance in The SAS System Version 9.0 (SAS Institute Inc. Cary, NC, USA).

\section{Results}

\section{Effect of culture media and $\mathbf{p H}$}

The mycelial growth rate on the four culture media in four days of incubation is shown in Figure 2.

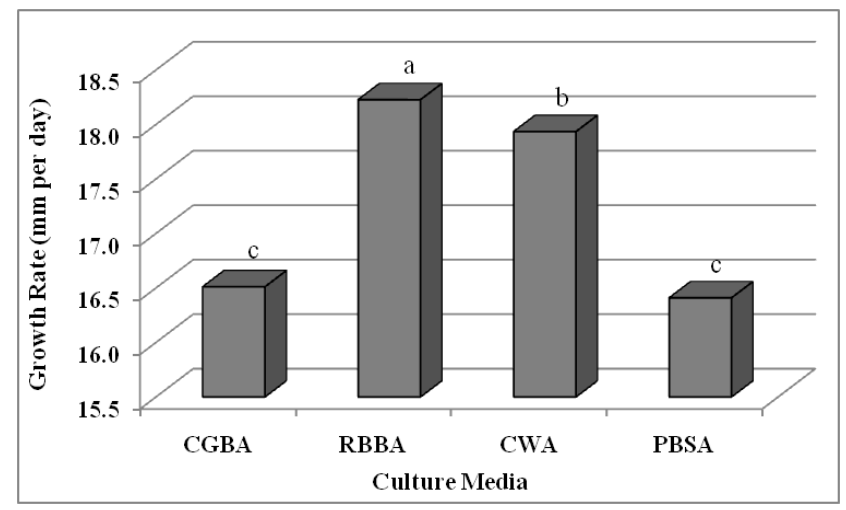

Figure-2. Mycelial growth rate of T. elegans on the different culture media; CGBA, corn grit broth agar; RBBA, rice bran broth agar; CWA, coconut water agar; PBSA potato broth sucrose agar at $\mathbf{p H}$ 6.0 in four days of incubation. Growth rates with the same letter are significantly comparable from each other at $5 \%$ level of significance.

Apparently, mycelia of $T$. elegans responded differently on the four culture media. Among these media, the highest mycelial growth rate was recorded in RBBA, followed by CWA. PBSA registered the lowest growth rate. Very thick mycelia were noted in RBBA, while thin mycelia were observed in CGBA (Figure 3).
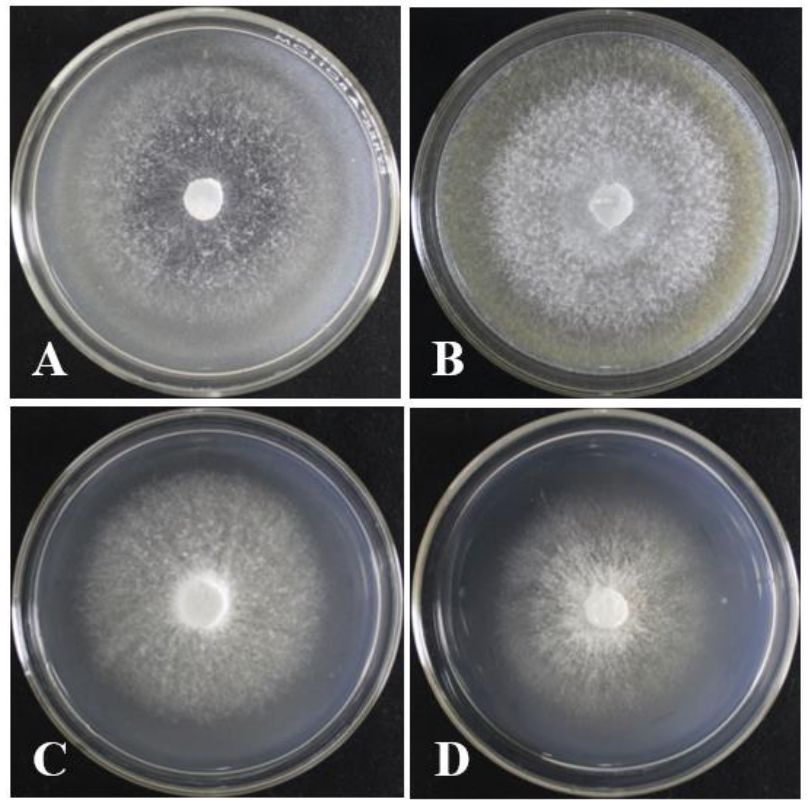

Figure-3. Mycelial growth of $T$. elegans on the different culture media: (A) CGBA, corn grit broth agar; (B) RBBA, rice bran broth agar; (C) CWA, coconut water agar; (D) PBSA, potato broth sucrose agar after four days of incubation. 
Notably, the $\mathrm{pH}$ levels ranging from 4 to 9 were found suitable for the growth of T. elegans mycelia (Figure 4). However, RBBA at $\mathrm{pH} 5.5$ to 6.5 produced the highest growth rate of mycelia after four days of incubation. Mycelia were compact and very thick for all $\mathrm{pH}$ levels (Figure 5).

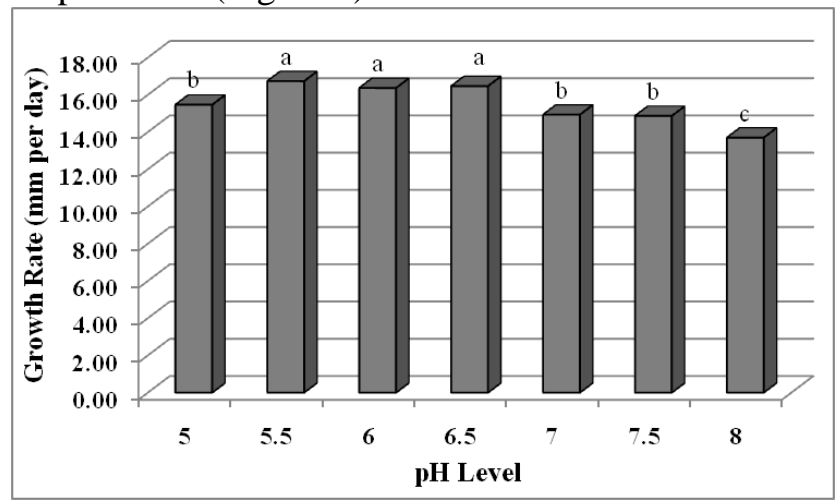

Figure-4. Mycelial growth rate of T. elegans on rice bran broth agar at different $\mathrm{pH}$ levels in four days of incubation. Growth rates with the same letter are significantly comparable from each other at $5 \%$ level of significance.

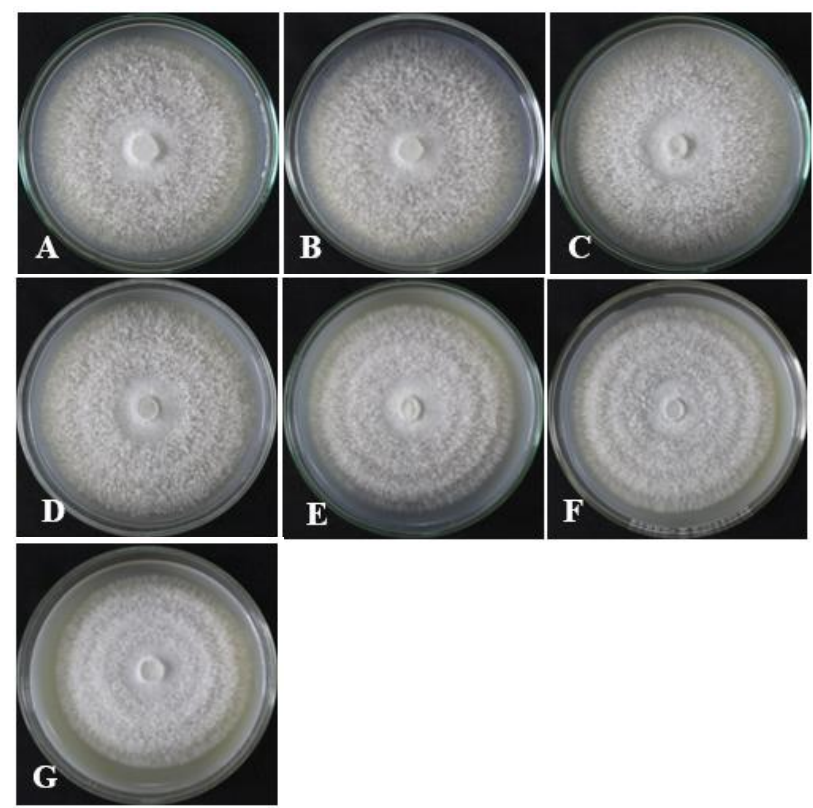

Figure-5. Mycelial growth response of T. elegans on rice bran broth agar at different $\mathrm{pH}$ levels: (A) 5.0; (B) 5.5 ; (C) 6.0; (D) 6.5; (E) 7.0; (F) 7.5; and (G) 8.0 after four days of incubation.

\section{Effect of physical factors}

The effects of environmental factors such as illumination, temperature and aeration on the growth of $T$. elegans mycelia were studied (Figure 6). In illumination, both artificially lighted and dark conditions were found to be favorable for the mycelial growth of T. elegans. However, mycelial density was observed thicker when exposed to lighted condition (Figure 7A). Cultures incubated at $30^{\circ} \mathrm{C}$ recorded the highest mycelial growth rate and produced very thick mycelia (Figure 7C). The mycelial growth was suppressed when incubated at $20^{\circ} \mathrm{C}$, while no mycelial growth was observed in those at $10^{\circ} \mathrm{C}$. However, mycelia in sealed plates had higher growth rate and thicker mycelia (Figure 7F) than those in unsealed plates.

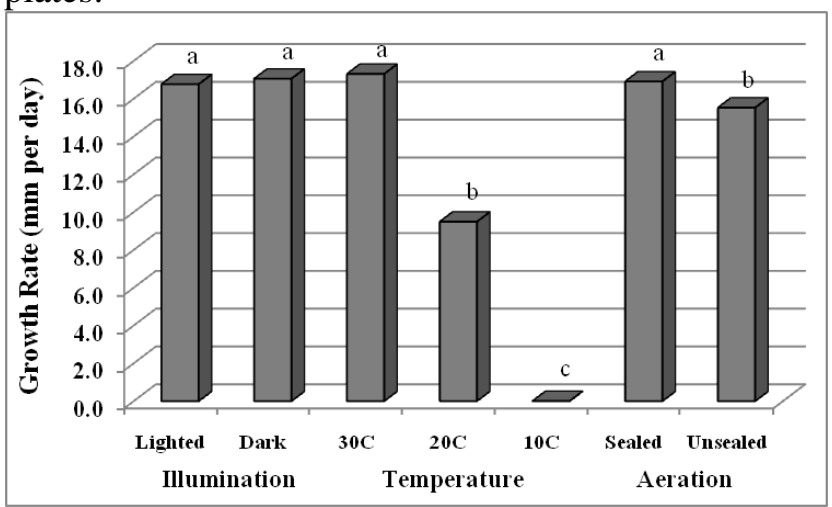

Figure-6. Mycelial growth rate of T. elegans on rice bran broth agar with pH 5.5 incubated at different physical factors in four days of incubation. Growth rates with the same letter in each physical factor are significantly comparable from each other at $5 \%$ level of significance.

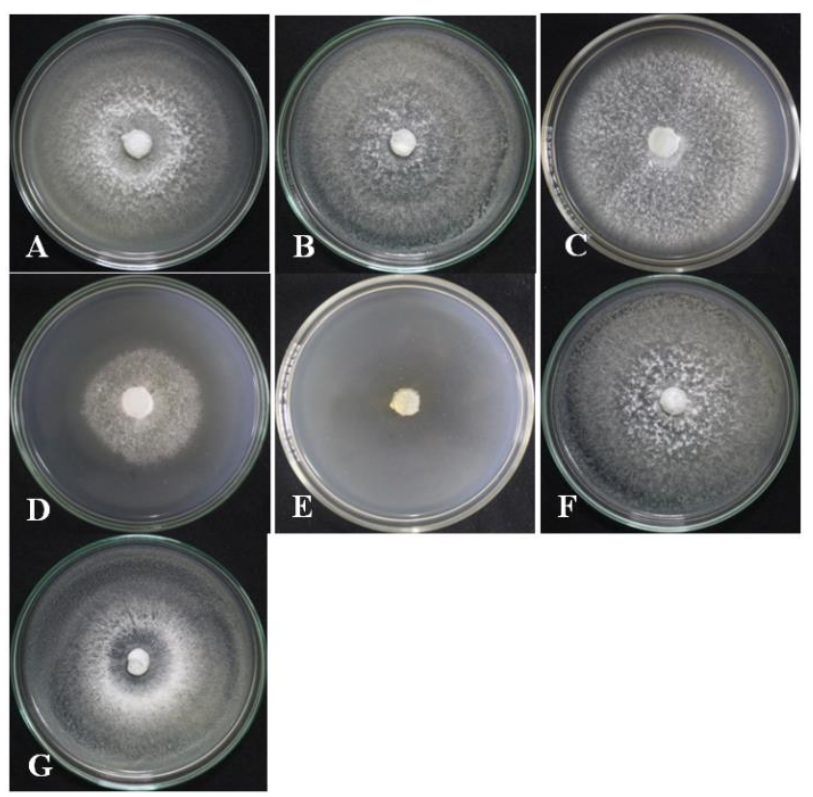

Figure-7. Culture plates of $T$. elegans on rice bran broth agar at pH 5.5 as affected by illumination [(A) lighted and (B) dark], temperature $\left[(C) 30^{\circ} \mathrm{C}\right.$, (D) $20^{\circ} \mathrm{C}$, and $\left.\left.(\mathrm{E}) \mathbf{1 0}^{\circ} \mathrm{C}\right)\right]$ and aeration $[(\mathrm{F})$ sealed and $(\mathrm{G})$ unsealed] conditions. 


\section{Grain spawn and fruiting body production}

The best granulated materials for grain spawn production was also evaluated (Table 1). Both cracked corn and sorghum seeds significantly recorded the shorter period of incubation ( 8 days) and showed very thick mycelia. Rice seeds had longer incubation period and thin mycelial density (Figure 8B).

Table-1. Number of days of incubation and mycelia density of $T$. elegans in the three spawn substrate

\begin{tabular}{|c|c|c|}
\hline Grain spawn & $\begin{array}{c}\text { Incubation Period } \\
\text { (day) }\end{array}$ & $\begin{array}{c}\text { Mycelial } \\
\text { density }\end{array}$ \\
\hline Cracked corn & $8.00 \pm 0.00^{\mathrm{a}}$ & ++++ \\
\hline Rice seeds & $9.00 \pm 0.00^{\mathrm{b}}$ & ++ \\
\hline Sorghum seeds & $8.00 \pm 0.00^{\mathrm{a}}$ & ++++ \\
\hline
\end{tabular}

Values are mean \pm SD of three replicates. Means having the same letter of superscript in the same column are significantly comparable from each other at 5\% level of significance. In a column mycelial density: very thin $(+)$, thin $(++)$, thick $(+++)$, very thick (++++).
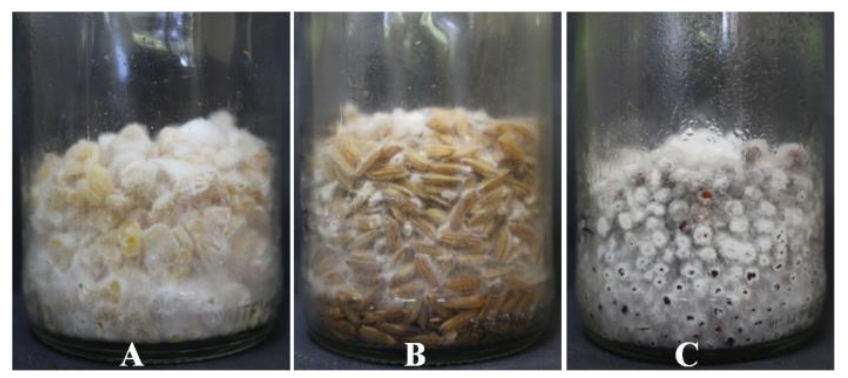

Figure-8. Mycelial ramification of $T$. elegans on different spawning materials: (A) cracked corn, (B) rice seeds, and (C) sorghum seeds 8 days after inoculation.

The most extensive period of incubation, on the other hand, was recorded in pure sawdust. After the full mycelial ramification of the substrate, the emergence and development of fruiting bodies was also observed and documented (Figure 10). From the very thick mycelial density, the primordia appeared 10 days post opening of the substrate bags. These primordia eventually developed into fruiting bodies, expanded and matured. Substrate formulation 4:6 produced the highest yield $(12.03 \mathrm{~g})$ with a corresponding biological efficiency of $2.41 \%$, but statistically comparable to $6: 4$ (10.30 g and $2.06 \%$, respectively).

However, after two days of prolonged incubation, very thick mycelia were also seen in rice seeds spawn. In fruiting body production, the incubation period, yield and biological efficiency in the different substrate formulations were determined (Table 2).
Substrate formulation $8: 2$ recorded the shortest incubation period, but statistically comparable to $6: 4$, 4:6, and 2:8. All formulations containing parts of rice straw had very thick growth of mycelia (Figure 9).

Table-2. Number of days of incubation, yield, and biological efficiency of $T$. elegans cultivated in the different formulations of sawdust and rice straw.

\begin{tabular}{|c|c|c|c|}
\hline $\begin{array}{c}\text { Substrate } \\
\text { (SD:RS) }\end{array}$ & $\begin{array}{c}\text { Incubation } \\
\text { Period (day) }\end{array}$ & $\begin{array}{c}\text { Yield / bag } \\
\text { (g) }\end{array}$ & $\begin{array}{c}\text { Biological } \\
\text { Efficiency (\%) }\end{array}$ \\
\hline $10: 0$ & $30.00 \pm 0.00^{\mathrm{a}}$ & $4.60 \pm 0.60^{\mathrm{d}}$ & 0.92 \\
\hline $8: 2$ & $26.33 \pm 0.58^{\mathrm{c}}$ & $9.27 \pm 0.51^{\mathrm{b}}$ & 1.85 \\
\hline $6: 4$ & $26.67 \pm 0.58^{\mathrm{c}}$ & $10.30 \pm 1.06^{\mathrm{ab}}$ & 2.06 \\
\hline $4: 6$ & $26.67 \pm 0.58^{\mathrm{c}}$ & $12.03 \pm 1.93^{\mathrm{a}}$ & 2.41 \\
\hline $2: 8$ & $27.00 \pm 0.00^{\mathrm{c}}$ & $7.43 \pm 0.90^{\mathrm{c}}$ & 1.49 \\
\hline $0: 10$ & $28.00 \pm 0.00^{\mathrm{b}}$ & $6.50 \pm 1.10^{\mathrm{c}}$ & 1.30 \\
\hline
\end{tabular}

Values are mean \pm SD of three replicates. Means having the same letter of superscript in the same column are significantly comparable from each other at $5 \%$ level of significance.

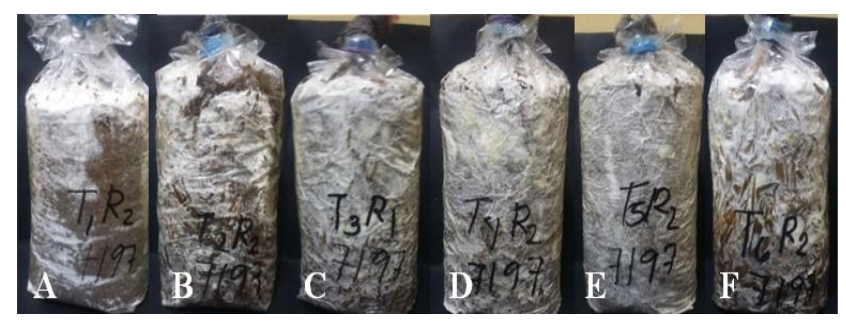

Figure-9. Mycelial growth of T. elegans in the different substrate formulations (SD:RS): (A) 10:0, (B) 8:2, (C) 6:4, (D) 4:6, (E) 2:8, (F) 0:10 after 30 days of incubation period.

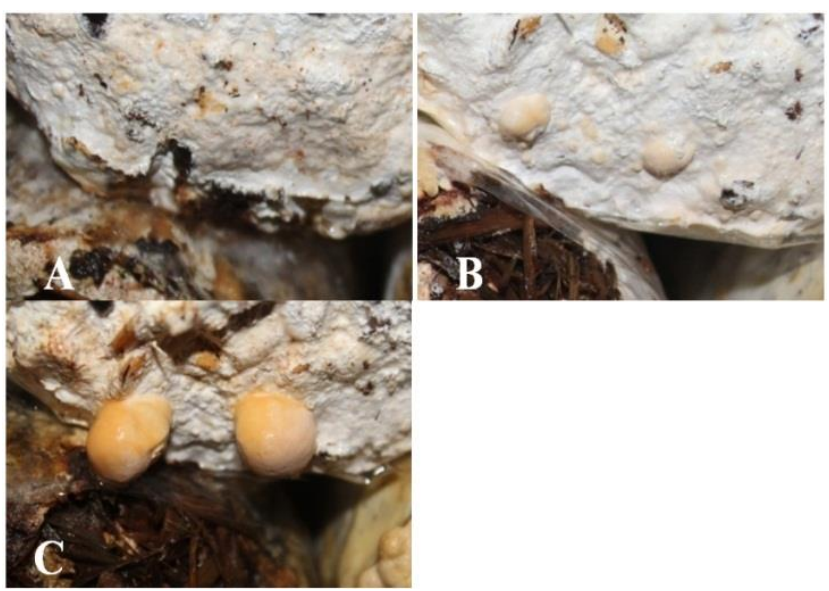

Figure-10. Fruiting body development of $T$. elegans, (A) very thick mycelia coat, (B) formation of primordia, (C) expansion and maturation of fruiting body. 


\section{Discussion}

The wild fruiting body of T. elegans was successfully tissue cultured on PDA plates and was labelled as BIL 7197. However, in order to obtain the most efficient growth, it is necessary to optimize the culture conditions of its mycelia. In the present study, the mycelial growth was evaluated first on the four culture media. RBBA was found to be the most suitable medium that promote efficient mycelial growth of $T$. elegans. This favourable response to RBBA could be accounted to the nutrient compositions of rice bran. Rice bran contains carbohydrates, dietary fiber, sugar, sucrose, glucose, fructose, protein, fats, minerals and vitamins (USDA, 2012).

In screening the suitable media for the six strains of Coriolus (Trametes) versicolor from Korea, PDA, yeast extract agar (YEA) and malt extract agar (MEA) produced the most efficient mycelial growth (Jo et al., 2010). However, T. versicolor (strain HTV-1) from Mexico has greater preference on MEA than PDA (Guerrero et al., 2011). However, in the previous works, we reported that Oudemansiella canarii luxuriantly grew on MEA and PBSA (Dulay and Damaso, 2017), while Lentinus strigosus mycelia favored Sabouraud dextrose agar (SDA) and CWA (Dulay et al., 2017). Polyporus grammocephalus produced the excellent mycelial growth of on MEA and CGBA (Dulay and Rivera, 2017). Based on the above findings, it is noteworthy to say that each mushroom has unique culture medium preference.

The $\mathrm{pH}$ of the medium also influences the growth of mycelia. This study established that the optimum $\mathrm{pH}$ for maximum growth of $T$. elegans mycelia was at $\mathrm{pH}$ 5.5 to 6.5. Kalaw et al. (2016) reported that most of the studied wild macrofungi from Central Luzon, Philippines had optimal $\mathrm{pH}$ at 6 to 7. On the other hand, the favorable $\mathrm{pH}$ for mycelial growth of $C$. versicolor and Ganoderma applanatum are within $\mathrm{pH}$ range of $4-6$ and $6-9$, respectively (Jo et al., 2010; Jo et al., 2009). Moreover, the favorable growth of mycelia of Oudemansiella radicata was obtained at pH 5 to 9, but pH 6 was the optimum (Kim et al., 2005).

Aside from nutritional requirements, the optimal environmental conditions were also evaluated. Although light is very essential for the growth of mycelia and production of fruiting bodies of mushrooms, it is not the most important factor that influenced the growth of T. elegans mycelia, since it was found to luxuriantly grow in either dark or lighted conditions. This corroborates with the study of Kalaw et al. (2016) who reported that out of 13 wild species and strains of Philippine wild macrofungi, mycelial growth of nine mushrooms were favorable in both lighted and dark conditions. Although nonphotosynthetic, fungi sense the different qualities and intensities of light (Idnurm and Heitman, 2005). Blue light-emitting diode (LED) was found to be the most effective illumination condition for efficient growth of mycelia and production of basidiocarp of Lentinus tigrinus (Damaso et al., 2018). However, one study reported that red and blue LED and dark were favourable for the fast growth of mycelia of Ganoderma lucidum.

Temperature is another important physical factor that influences the mycelial growth of mushroom. The superior mycelial growth at $30^{\circ} \mathrm{C}$ strongly indicates that $T$. elegans is indeed a tropical species. This response is the same to that of $C$. versicolor, which showed optimum temperature at $25-30^{\circ} \mathrm{C}$ (Jo et al., 2010). Moreover, $32^{\circ} \mathrm{C}$ was the optimum temperature for the efficient mycelial growth of Philippine mushrooms including G. lucidum strains A and B, $L$. tigrinus, Volvariella volvacea strain Rang-ayan, Coprinopsis cinerea strain Sto. Domingo, and Lentinus sajor-caju (Dulay et al., 2012a; Kalaw et al., 2016). These findings imply that the response of mushroom mycelia to temperature is dependent on the species and strain type.

The last physical factor evaluated in the present study was aeration. Apparently, aeration significantly affects the mycelial growth of $T$. elegans. The results of the present work indicate that aeration is one of the most important physical factor that affects the mycelial colonization of T. elegans. This favourable response to sealed condition is congruent to the reports of Dulay et al. (2017) and Magday et al. (2014) that sealed condition registered the faster growth of mycelia of $L$. strigosus, and G. lucidum. Altogether, this paper demonstrated that the mycelia of $T$. elegans grew efficiently in either lighted or dark, at $30^{\circ} \mathrm{C}$, and in sealed condition.

Prior to fruiting body production, it is necessary to determine the best grain spawn material. Grain spawn is a carrier of mycelia that serves as inoculant of fruiting bags for mushroom cultivation. Accordingly, both cracked corn and sorghum seeds were found to be the best substrate for grain spawn production. Rice seeds were also considered a very good substrate. The thin mycelial density in rice seeds at earlier period of incubation could be due to the rice husk that serves as 
barrier in penetrating the nutritious part of the grain by the mycelia. The same response in rice seeds was observed in L. strigosus and L. tigrinus (Dulay et al., 2017; Dulay et al., 2012a).

Fruiting body performance of $T$. elegans was investigated using the different sawdust and rice straw-based formulations. Noticeably, the biological efficiencies of $T$. elegans obtained in this study were very low when compared to the commercially cultivated mushrooms. This case is also the same to that of T. versicolor having $3.2 \%$ biological efficiency when grown in pure oak sawdust, but increases to $20.3 \%$ when cultivated in oak sawdust supplemented with $10 \%$ sorghum kernels, $10 \%$ wheat bran, and $2 \%$ gypsum (Guerrero et al., 2011). Moreover, rice bran improves the biological efficiencies of Coprinus comatus, S. commune, G. lucidum, and L. strigosus (Dulay et al., 2012b; Kalaw et al., 2017; Dulay et al., 2017). Accordingly, the effect of supplementation of substrate using rice bran is of great interest to enhance the bio-efficiency of T. elegans.

\section{Conclusion}

In conclusion, the optimum cultural conditions for luxuriant growth of $T$. elegans mycelia are successfully established in RBBA at $\mathrm{pH}$ ranging from 5.5 to 6.5 , when incubated in either lighted or dark, at $30^{\circ} \mathrm{C}$, and in sealed conditions. Both cracked corn and sorghum seeds serve as the best spawning materials. The fruiting body can be cultivated using formulated sawdust and rice straw as substrate. However, the yield and bio-efficiency are very low, thus, we need to investigate other cultivation techniques such as using enriched substrates and other physical factors in order to improve the biomass yield. Furthermore, the bioactivities and functionalities must also be studied in our intention to establish the role of T. elegans in pharmaceutical and nutraceutical field.

\section{Acknowledgement}

The Department of Science and Technology - Science Education Institute (DOST-SEI) in the Philippines is gratefully acknowledged for the scholarship granted to the primary author.

Disclaimer: None.

Conflict of Interest: None.

Source of Funding: None.

\section{References}

Aina D, Olawuyi O, Mensah-Agyei G, Laiya A and Adeoye-Isijola M, 2016. Comparative phytochemical evaluation, antimicrobial and antioxidant properties of methanolic and ethanolic extracts of Daedalea elegans - a Nigerian mushroom. Adv. Pharm. J. 1(2): 38-42.

Chang ST and Miles PG, 1992. Mushrooms biology a new discipline. Mycologist. 6: 64-65.

Chu KKW, Ho SSS and Chow AHL, 2002. Coriolus versicolor: a medicinal mushroom with promising immunotherapeutic values. J. Clin. Pharmacol. 42(9): 976-984.

Collins RA and Ng TB, 1997. Polysaccharopeptide from Coriolus versicolor has potential for use against human immunodeficiency virus type 1 infection. Life Sci. 60(25): PL383-PL387.

Cui J and Chisti Y, 2003. Polysaccharopeptides of Coriolus versicolor: physiological activity, uses and production. Biotechnol. Adv. 21: 109-122.

Damaso EJ Jr., Dulay RMR, Kalaw SP and Reyes RG, 2018. Effects of color light emitting diode (LED) on the mycelial growth, fruiting body production, and antioxidant activity of Lentinus tigrinus. CLSU Int. J. Sci. Technol. 3(2): 9-16.

Dulay RMR and Damaso EJ Jr., 2017. The first report on the successful rescue and domestication of Philippine wild mushroom Oudemansiella canarii (BIL 9137). Int. J. Biol. Pharm. Allied Sci. 6(12): 2359-2369.

Dulay RMR, Parungao AG IV, Kalaw SP and Reyes RG, 2012b. Aseptic cultivation of Coprinus comatus (O. F. Mull.) Gray on various pulp and paper wastes. Mycosphere. 3(3): 392-397.

Dulay RMR, Rivera AGC and Garcia EJB, 2017. Mycelial growth and basidiocarp production of wild hairy sawgill Lentinus strigosus, a new record of naturally occurring mushroom in the Philippines. Biocatal. Agric. Biotechnol. 10: 242246.

Dulay RMR and Rivera AGC, 2017. Mycelial growth and fruiting body production of Philippine (CLSU) strain of Polyporus grammocephalus (BIL7749). Biocatal. Agric. Biotechnol. 11: 161165.

Dulay RMR, Kalaw SP, Reyes RG, Cabrera EC and Alfonso NF, 2012a. Optimization of culture conditions for mycelial growth and basidiocarp production of Lentinus tigrinus (Bull.) Fr., a new record of domesticated wild edible mushroom in 
the Philippines. Philipp. Agric. Sci. 95: 278-285.

Guerrero DG, Martinez VE and Almaraz RDT, 2011. Cultivation of Trametes versicolor in Mexico. Micol. Apl. Int. 23(2): 55-58.

Guzman CDM, Baltazar MM, Sanchez AJI, Linsangan MG and Dulay RMR, 2018. Molecular identification of four wild higher basidiomycetes collected in Mt. Mingan, Gabaldon, Nueva Ecija, Philippines. J. Biodivers. Environ. Sci. 13(6): 4651.

Idnurm A and Heitman J, 2005. Light controls growth and development via a conserved pathway in the fungal kingdom. PLoS Biol. 3(4): 95.

Jing D, Li P, Stagnitti F and Xiong X, 2007. Optimization of laccase production from Trametes versicolor by solid fermentation. Can. J. Microbiol. 53(2): 245-251.

Jo WS, Chu YJ, Cho HD, Park SD, Yoo YB and Seok SJ, 2009. Culture conditions for the mycelial growth of Ganoderma applanatum. Mycobiol. 37(2): 94-102.

Jo WS, Kang MJ, Choi SY, Yoo YB, Seok SJ and Jung HY, 2010. Culture conditions for mycelial growth of Coriolus versicolor. Mycobiology. 38(3): 195202.

Johnsy G and Kaviyarasana V, 2011. Antimicrobial and antioxidant properties of Trametes gibbosa (Pers.) Fr. J. Pharm. Res. 4: 3939-3942.

Kalaw SP, Alfonso DO, Dulay RMR, De Leon AM, Undan JQ, Undan JR and Reyes RG, 2016. Optimization of culture conditions for secondary mycelial growth of wild edible mushrooms from selected areas in Central Luzon, Philippines. Curr. Res. Environ. Appl. Mycol. J. Fungal Biol. 6(4): 277-287.

Kalaw SP, Nabor R, Dulay RMR, Undan JR, Undan JQ, De Leon AM and Reyes RG, 2017. Mycelia and fruiting body performance of Philippine wild strains of Ganoderma lucidum and Schizophyllum commune on rice bran enriched rice straw based substrates. Int. J. Biol. Pharm. Allied Sci. 6(6): 1210-1219.

Kamiyama M, Horiuchi M, Umano K, Kondo K, Otsuka Y and Shibamoto T, 2013. Antioxidant / anti-inflammatory activities and chemical composition of extracts from the mushroom Trametes versicolor. Int. J. Food Sci. Nutr. 2: 8591.

Kim SB, Kim SH, Lee KR, Shim JO, Lee MW, Shim MJ, Lee UY and Lee TS, 2005. The optimal culture conditions for the mycelial growth of
Oudemansiella radicata. Mycobiol. 33(4): 230234.

Knezevic A, Zivkovic L, Stajic M, Vukojevic J, Milovanovic I and Spremo-Potparevic B, 2015. Antigenotoxic effect of Trametes spp. extracts against DNA damage on human peripheral white blood cells. Sci. World J. Article ID 146378.

Liu Z, Zhang K, Ke Z, Wu Y and Li X, 2016. Optimisation of medium and culture conditions for the production of antifungal substances to Colletotrichum musae by Trametes elegans SR06. Biocontrol Sci. Technol. 26(11): 1538-1551.

Liwanag JMG, Santos EE, Flores FR, Clemente RF and Dulay RMR, 2017. Species listing of macrofungi in Angat Watershed Reservation, Bulacan Province, Luzon Island, Philippines. Int. J. Biol. Pharm. Allied Sci. 6(5): 1060-1068.

Magday Jr. JC, Bungihan ME and Dulay RMR, 2014. Optimization of mycelial growth and cultivation of fruiting body of Philippine wild strain of Ganoderma lucidum. Curr. Res. Environ. Appl. Mycol. J. Fungal Biol. 4(2): 162-172.

Nanglihan KEMV, Dulay RMR and Kalaw SP, 2018. Myko-actives and functional activities of Philippine wild mushroom Trametes elegans. Int. J. Biosci. 13(5): 402-408.

Ren M, Karim MR, Islam MF, Habib MR and Hossain MT, 2006. Phytochemical and antitumor investigation on Trametes gibbosa. Int. Res. J. Pharm. 1: 342-345.

Shahbazyan V, Shenbhagaraman R, Kaviyarasan V, Gunasundari D, Radhika K, Dandapani R and Loganathan KJ, 2017. Antioxidant, antibacterial and antiproliferative effect of Trametes gibbosa. J. Phytol. 2: 022-028.

Tavares APM, Coelho MAZ, Coutinho JAP and Xavier ARMB, 2005a. Laccase improvement in submerged cultivation: induced production and kinetic modeling. J. Chem. Technol. Biotechnol. 80: 669-676.

Tavares APM, Agapito MSM, Coelho MAZ, Lopes da Silva JA, Barros-Timmons A, Coutinho JAP and Xavier AMRB, 2005b. Selection and optimization of culture medium for polysaccharide production by Coriolus (Trametes) versicolor. World J. Microbiol. Biotechnol. 21: 1499-1507.

Teoh YP and Mashitah MD, 2012. Screening of antifungal activities from genera Trametes against growth of selected wood-decaying fungi from Malaysia. Aust. J. Basic Appl. Sci. 6(1): 79-85. 
Trupkin S, Levin L, Forchiassin F and Viale A, 2003. Optimization of a culture medium for ligninolytic enzyme production and synthetic dye decolorization using response surface methodology. J. Ind. Microbiol. Biotechnol. 30(12): 682-690.

United States Department of Agriculture (USDA), 2012. Nutritional info of rice bran, crude vs. oat bran, raw. SkipThePie.org. Available at http://skipthepie.org/cereal-grains-and-pasta/ricebran-crude/compared-to/oat-bran-raw/

\section{Contribution of Authors}

Dulay RMR: Conceptualization of the study, literature review, data interpretation and analysis and manuscript writing Alcazar AA: Literature review, experimental design, data collection and analysis Kalaw SP \& Reyes RG: Research design and methodology assessment and manuscript critiquing

Cabrera EC: Manuscript critiquing, final reading and approval 